\title{
Research on effectiveness of closed area method of cross-level hierarchical control structure in power grid
}

\author{
Chuang Tian ${ }^{1, a}$, Kaifeng Zhang, ${ }^{1, b}$, Kun Yuan ${ }^{1, c}$ and Chunyu Chen ${ }^{1, d}$ \\ ${ }^{1}$ Key Laboratory of Measurement and Control of CSE (School of Automation, Southeast University), \\ Nanjing 210096, China \\ azailushangtch@163.com, bkaifengzhang@seu.edu.cn, 'kyuan@seu.edu.cn, d230159105 @ \\ seu.edu.cn
}

\begin{abstract}
Keywords: Cross-level hierarchical control; Closed area method; Direct-dispatching generator; Area control error (ACE); Load frequency control model; Digital simulation.

Abstract. Due to cross-level hierarchical control is usually adopted in China Power Grid, the regulating of direct-dispatching generators would have impacts on the calculation of ACE of the province, in which direct-dispatching generators locate. Closed area method that direct-dispatching generators are excluded from the provincial control area has been presented to solve the impact. However, there are not adequate theoretical explanations aimed at the method. This paper will show a theoretical proof of the necessity and effectiveness of the closed area method in detail with area control model. Then digital simulation on how closed method is applied in actual power grids will be carried out with load frequency control model, the result shows that closed area method significantly reduces the impacts on ACE of provincial control area from direct-dispatching generations, which proves closed area method to be feasible and effective.
\end{abstract}

\section{Introduction}

Usually, hierarchical control structure [1] will be adopted typically in actual power grids. For example, in three level hierarchical control structure, the first level controller is only responsible for the coordination between the second level controllers, and the second level controller is only responsible for the coordination between the third level controllers. Specially, the first level controller will not interface the behavior of the third level controllers directly. However, there are such units in the actual power system in our country that they do not follow the instruction of province in which they locate and they are controlled by regional power grid directly instead. The special units are called direct-dispatching generators [2] and they make hierarchical control structure of power grid in our country different. On the one hand, the regional power grid control center issues the instruction reference value to provincial power grid control center and provincial power grid will decide the regulating action of the AGC units then. On the other hand, the regional power grid control center can also issue the instruction reference value to direct-dispatching generators directly according to related control target. Obviously, this special hierarchical control structure quite differs from conventional hierarchical control structure and this special structure is also called cross-level hierarchical control structure.

In cross-level hierarchical control structure, Tie line Bias Frequency Control (TBC) $[3,4,5]$ is the widely used control model to guarantee the steady state of tie-line and system frequency of interconnected power grids. In order to solve the problem that direct-dispatching generators mentioned above may have impacts on $\mathrm{ACE}[6,7,8,9]$ of provincial power grid when calculating ACE, "closed area" method is proposed in reference [10] that direct-dispatching generators will be excluded from the provincial control area. Tie-lines between generators mentioned above and provincial control area are called generalized tie-lines. However, there are not detailed elaboration in reference [10]. Reference [11] also proposes the related concept of "closed area" and "generalized tie-lines" and gives the explanation with the use of simple area model. The explanation shows that 
variable quantity of active power on generalized tie-lines is added to tie-lines of provincial power grid when calculating ACE after "closed area" method is used. Accordingly, the proposal of "closed area" and "generalized tie-lines" can solve the contradiction between regulating of direct-dispatching generators and AGC regulating in provincial power grid effectively. However, the explanation and conclusion here cannot explain how "closed area" method eliminates the impacts on area control error of provincial power grid from direct-dispatching generators clearly.

It can be seen that "closed area" method has been proposed and applied, but there are still not clear elaboration and powerful theoretical proof. Consequently, the effectiveness of "closed area" method will be elaborated in theory in cross-level hierarchical control and related digital simulation will be used to prove the result.

\section{Introduction of closed area method}

In China, the national, regional and provincial LDCs (Load Dispatch Center) all have the right to control power plants. As shown in Fig. 1, direct-dispatching power plants locate in corresponding provincial power grid.

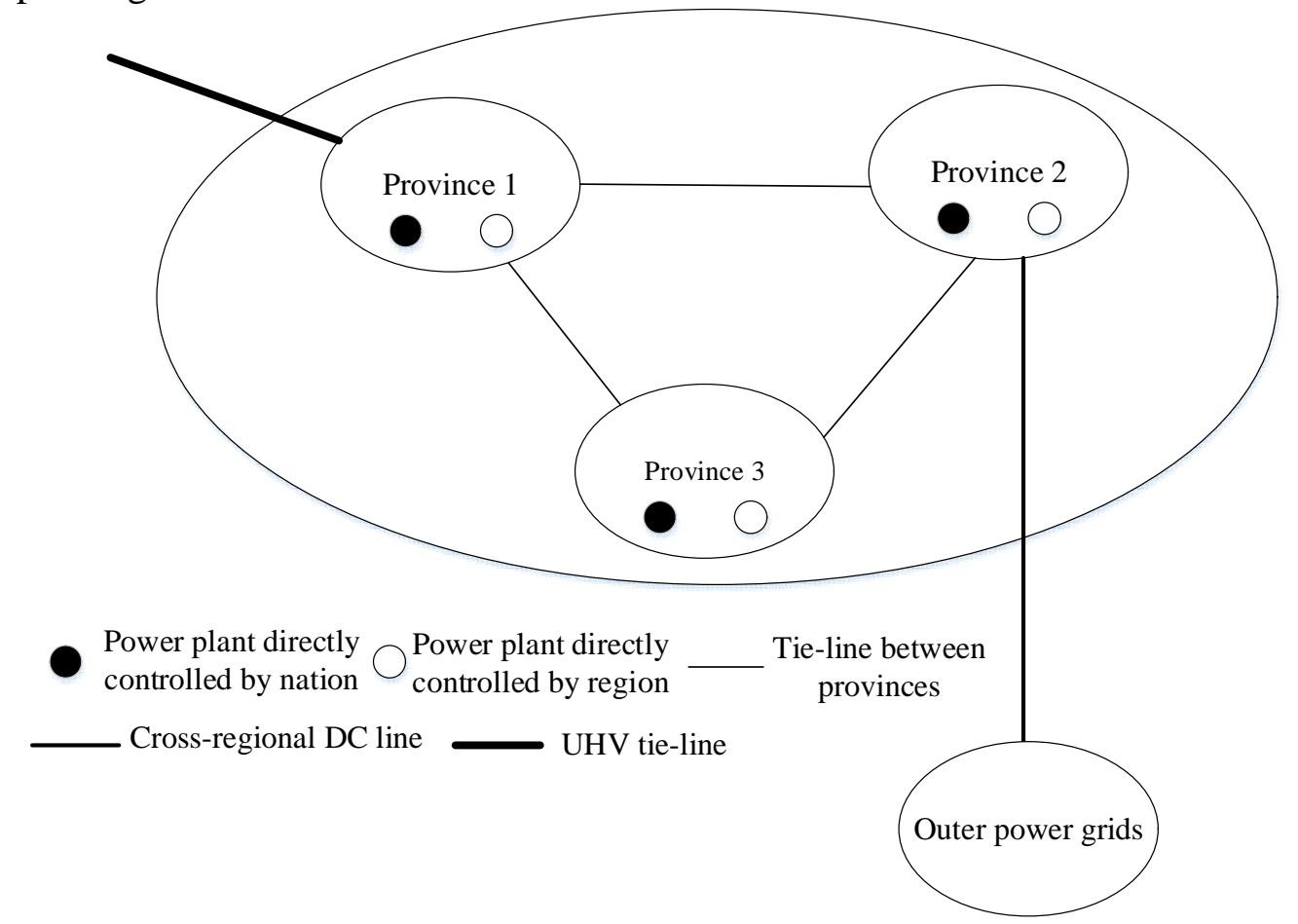

Fig. 1 Geographic area of multi control area of interconnected power grid

As direct-dispatching generators locate in each province, each provincial control area has no choice but to guarantee the balance of both generator (including direct-dispatching power plants which locate in this province) and system load by its own regulating. The regulating of direct-dispatching generators which is controlled by superior dispatching control center may be incompatible with the regulating of AGC generators in provincial control area. "Closed area" method is such an effective method that it can solve the contradiction well and the specific implement is as follows:

Direct-dispatching power plants will be excluded from the provincial control area and direct-dispatching area (including regional control area and national control area) will be created thus. Provincial control area will be changed into so-called "closed area" after direct-dispatching power plants have been excluded. Tie-lines between direct-dispatching control area and each closed area are called "generalized tie-lines". Thus, variable quantity of active power on generalized tie-lines will be added to tie-lines of provincial power grid when calculating ACE. It can be shown in Fig.2: 


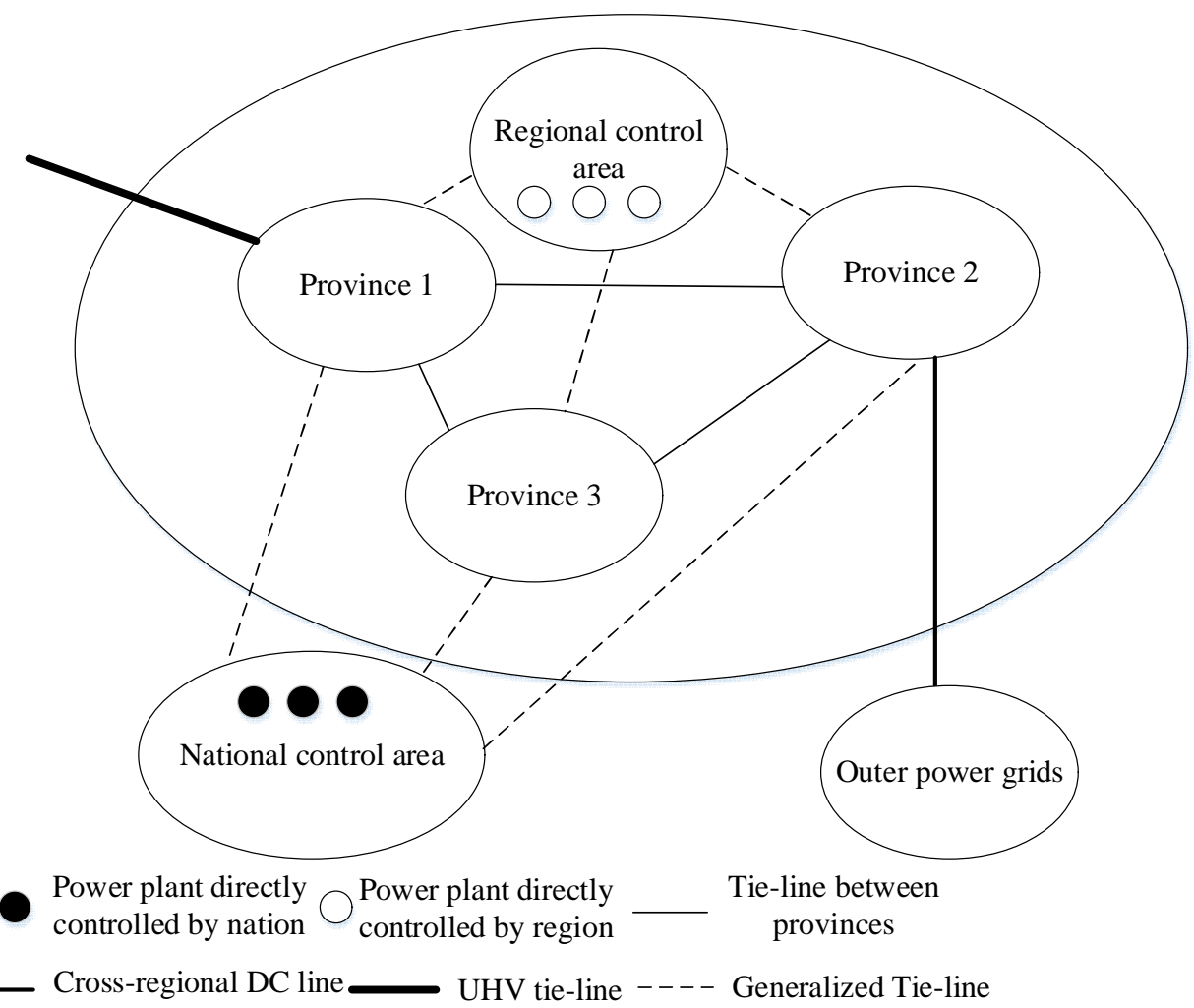

Fig. 2 Closed area of multi control area of interconnected power grid

According to the comparison of case 1 in which "closed area" method is not used and case 2 in which "closed area" method is adopted in provincial control area of interconnected power grid, we can find that "closed area" method can exclude direct-dispatching power plants from provincial control area in which direct-dispatching power plants locate in logic.

\section{Analysis of the effectiveness of closed area method}

In this section, a specific area control model will be used to help the analysis. The analysis will show how direct-dispatching generators influence the ACE of provincial control area in which they locate without the use of "closed area" method. Then, the analysis will also show how "closed area" method solves the contradiction between direct-dispatching generators and AGC generators in provincial control area.

As shown in Fig. 3, there are two independent operation areas (area A and area B) connected with one tie-line. The outermost oval area indicates regional control area. Both area A and area B indicate provincial control area. Specifically, area A indicates a typical provincial control area in which there is a provincial unit $\mathrm{A}$ and a direct-dispatching unit $\mathrm{I}$. And both unit $\mathrm{I}$ and unit $\mathrm{A}$ are connected by one tie-line. Area B indicates a provincial control area in which there is a provincial unit B only. 


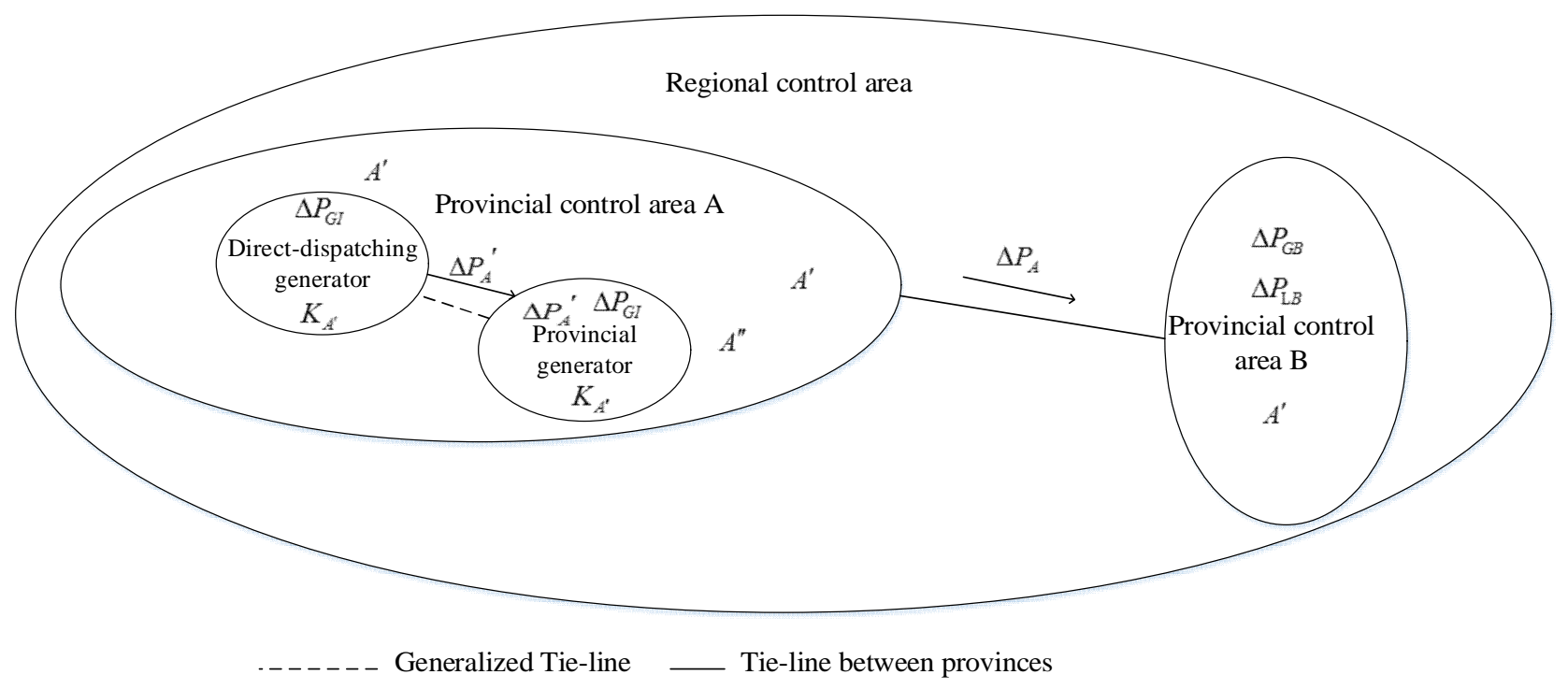

Fig. 3 Regional and Provincial control area

In addition, $K_{A}, K_{A^{\prime}}, K_{A^{\prime \prime}}$ and $K_{B}$ indicate frequency characteristic coefficients of provincial control area $\mathrm{A}$, regional control area $A^{\prime}$, closed area $A^{\prime \prime}$ and provincial control area $\mathrm{B} ; \Delta P_{G I}, \Delta P_{G A}$ and $\Delta P_{G B}$ indicate variable quantity of active power of direct-dispatching unit I, provincial unit A which locates in province $\mathrm{A}$ and provincial unit $\mathrm{B}$ which locates in province $\mathrm{B} ; \Delta P_{L A}$ and $\Delta P_{L B}$ indicate variable quantity of active power of loads in province $\mathrm{A}$ and loads in province $\mathrm{B} ; \Delta P_{A}^{\prime}$ stands for variable quantity of active power on generalized tie-line; $\Delta P_{A}$ stands for variable quantity of active power on tie-line between provinces; $\Delta f$ stands for the actual frequency deviation.

Analysis of active power/frequency control of power grid without closed area method. In provincial control area A and provincial control area B, two equations $[12,13]$ can be gotten as follows:

$$
\left\{\begin{array}{l}
\Delta P_{G A}+\Delta P_{G I}-\Delta P_{L A}-\Delta P_{A}=K_{A} \bullet \Delta f \\
\Delta P_{G B}-\Delta P_{L B}+\Delta P_{A}=K_{B} \bullet \Delta f
\end{array} .\right.
$$

If $K_{\Sigma}=K_{A}+K_{B}$, then

$$
\begin{gathered}
\Delta f=\frac{\left(\Delta P_{G I}+\Delta P_{G A}-\Delta P_{L A}\right)+\left(\Delta P_{G B}-\Delta P_{L B}\right)}{K_{\Sigma}}, \\
\Delta P_{A}=\frac{K_{A} \bullet\left(\Delta P_{L B}-\Delta P_{G B}\right)-K_{B} \bullet\left(\Delta P_{L A}-\Delta P_{G I}-\Delta P_{G A}\right)}{K_{\Sigma}}
\end{gathered} .
$$

In TBC control model, if it is assumed that the frequency deviation coefficient of each region is completely equal to the natural frequency characteristic coefficient, ACE of area A and area B can be defined as:

$$
\left\{\begin{array}{l}
E_{A}=K_{A} \bullet \Delta f+\Delta P_{A} \\
E_{B}=K_{B} \bullet \Delta f-\Delta P_{A} .
\end{array}\right.
$$

Put Eq. 2, Eq. 3 into Eq. 4, ACE of area A is described as following: 


$$
E_{A}=\Delta P_{G I}+\alpha
$$

Where, $\alpha=\Delta P_{G A}-\Delta P_{L A}$

$\alpha$ reflects the unbalance quantity of active power of area A after direct-dispatching has been excluded.

As can be seen from Eq. 5, when the output of direct-dispatching generator controlled by superior dispatching control center changes (that is to say $\Delta P_{G I} \neq 0$ ), ACE of provincial control area in which direct-dispatching generator locates will be influenced. As a result, ACE of provincial control area cannot reflect the actual unbalance quantity of active power.

Analysis of active power/frequency control of power grid with closed area method. In order to eliminate the impacts on provincial generators from direct-dispatching generators, direct-dispatching generators will be excluded from provincial control area in provincial control model. As shown in Fig. 3 , closed area $A^{\prime \prime}$ will be created. In addition, a new independent area $A^{\prime}$ will be created which consists of direct-dispatching generators and that is also called regional control area. There are two balances in area A.

Active balance of regional control area $A^{\prime}$ :

$$
\Delta P_{G I}-\Delta P_{A}^{\prime}=K_{A^{\prime}} \bullet \Delta f
$$

Active balance of closed area (updated provincial control area) $A^{\prime \prime}$ :

$$
\Delta P_{G A}-\Delta P_{L A}-\Delta P_{A}+\Delta P_{A}^{\prime}=K_{A^{\prime \prime}} \bullet \Delta f \text {. }
$$

According to Eq. 4, Eq. 7, ACE of closed area $A^{\prime \prime}$ can be described as:

$$
A C E_{A^{\prime \prime}}=K_{A^{\prime \prime}} \bullet \Delta f-\Delta P_{A}^{\prime}+\Delta P_{A} .
$$

Put Eq. 6 into Eq. 8, ACE of closed area $A^{\prime \prime}$ can also be described as:

$$
A C E_{A^{\prime \prime}}=\left(\Delta P_{A}+K_{A} \bullet \Delta f\right)-\Delta P_{G I} \text {. }
$$

Where, $K_{A}=K_{A^{\prime}}+K_{A^{\prime \prime}}$

Considering Eq. 4, Eq. 5, Eq. 9, ACE of closed area $A^{\prime \prime}$ can be calculated as:

$$
A C E_{A^{\prime \prime}}=\alpha \text {. }
$$

Where, $\alpha=\Delta P_{G A}-\Delta P_{L A}$

We can see from Eq. 10, the use of "closed area" method makes calculation of ACE of updated provincial control area no longer related to variable quantity of active power of direct-dispatching generators.

Comparing Eq. 5, Eq. 10, it can be found that when the "closed area" method is not used, the calculation of ACE of provincial control area in which direct-dispatching generator locates will include variable quantity of active power on direct-dispatching generators. However, after "closed area" method is used, the calculation of ACE of provincial control area will be not relevant to variable quantity of active power on direct-dispatching generators. Thus, it can be concluded that "closed area" method can effectively eliminates the impacts on ACE of provincial control area from direct-dispatching generators in theory. 


\section{Simulation verification}

In this section, with the help of Matlab/Simulink tools, load frequency control model will be taken to analysis the two cases of power grids (with "closed area" and without "closed area"). The simulation result indicates that "closed area" method can solve the contradiction between the regulating of direct-dispatching generators and AGC regulating in the provincial control area in which direct-dispatching generator locates effectively.

The traditional load frequency control model [14] can be shown in Fig. 4.

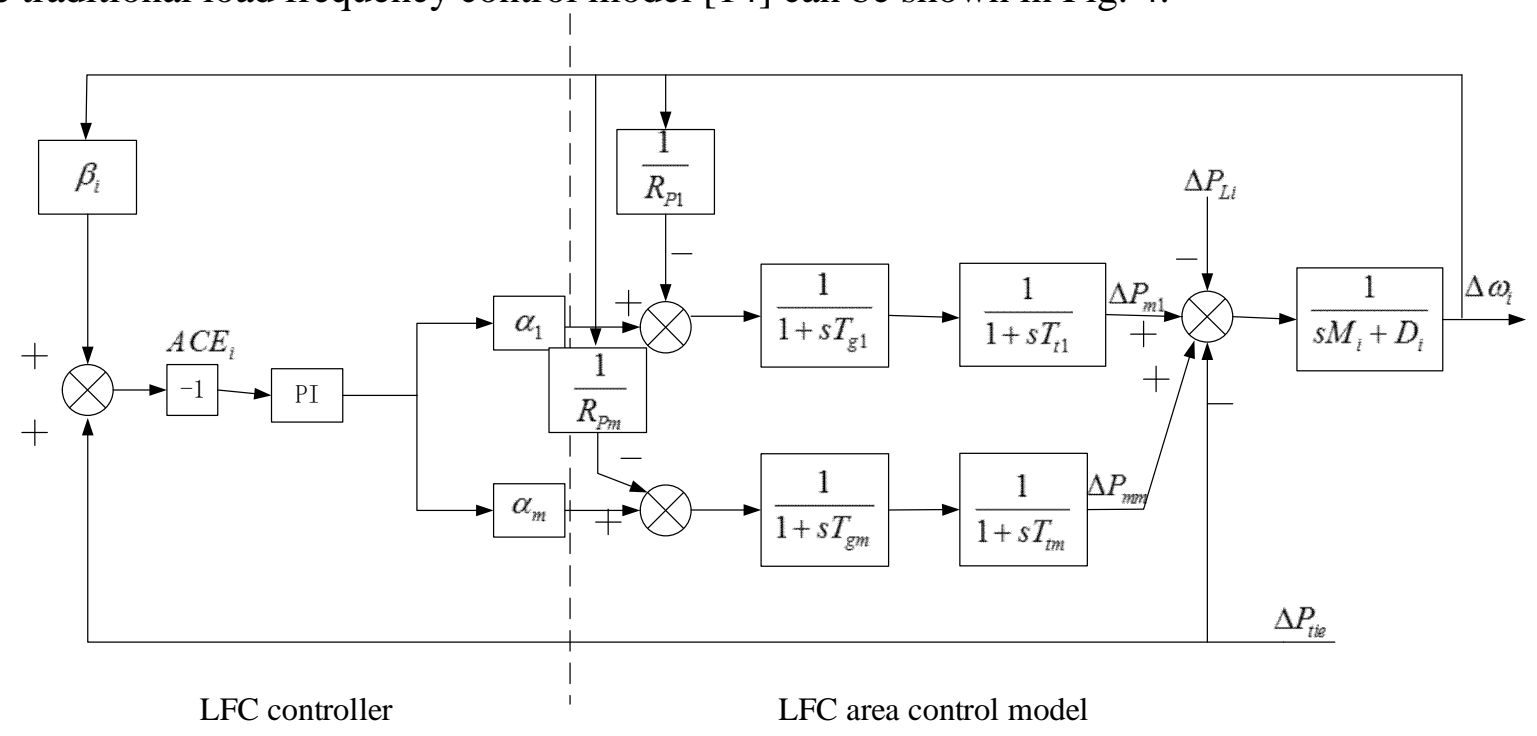

Fig. 4 Traditional load frequency control model

As shown in Fig. 4, the right part of the dotted line shows the load frequency control model of the ith area. And the left part represents the load frequency controller. In the previous model, all generators in the area will be equivalent with one equivalent machine and all the outputs of mechanical power of all steam turbines will work on the equivalent machine. In addition, D indicates the system load-damping coefficient; $M$ indicates the area inertia constant; both Turbine and governor are expressed by first-order inertia and the inertia time constants are $T_{t}$ and $T_{g} ; R_{p}$ indicates the speed reduction rate of the generator governor; $\beta$ indicates the frequency response characteristic of the region; $\alpha$ indicates the assigned coefficient to each generator assigned by AGC regulating. After provincial control area A and provincial control area B in Fig. 3 have be implemented by traditional load frequency control model in Fig. 4, load frequency control model of interconnected power grids can be gotten and shown in Fig. 5. 


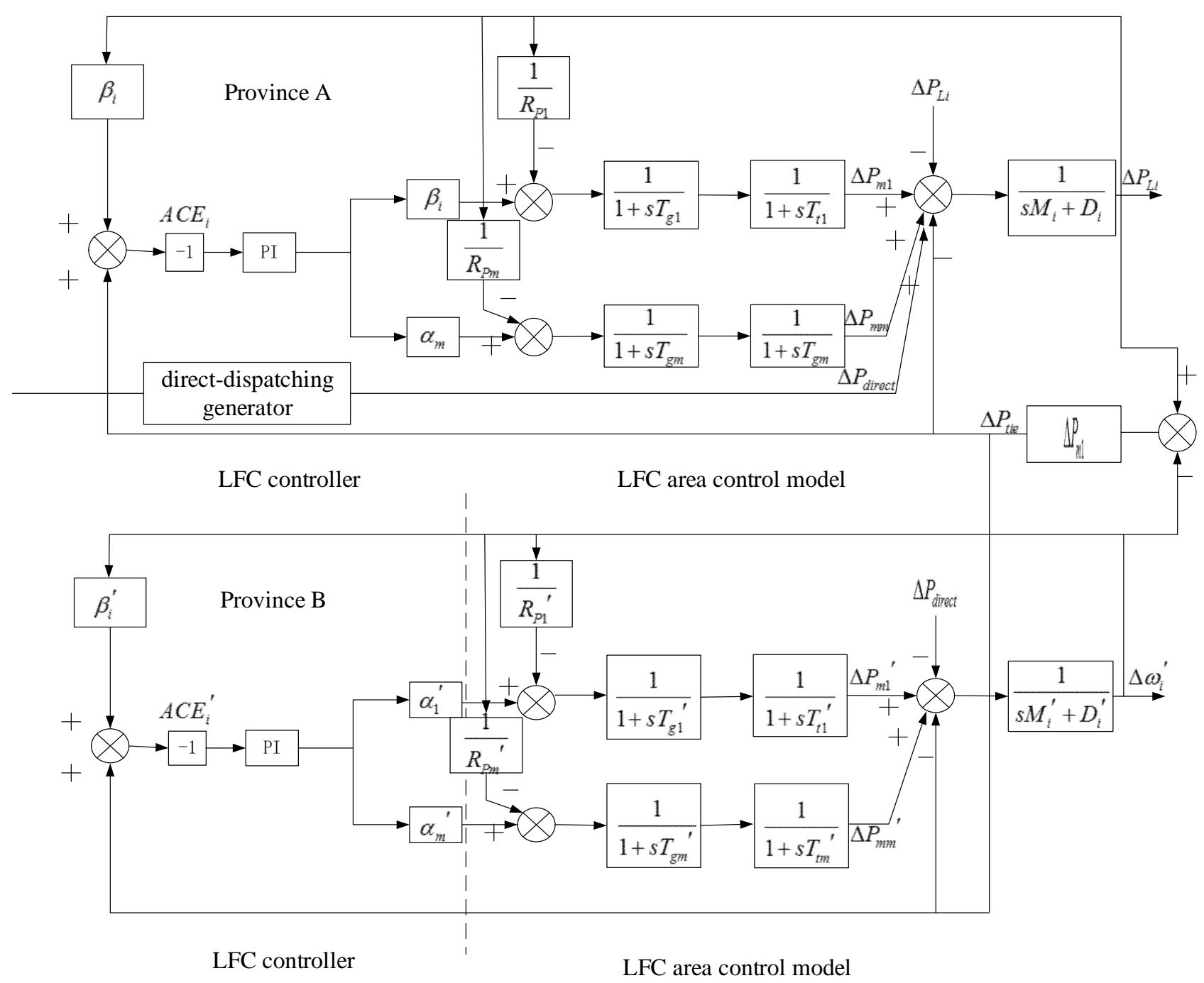

Fig. 5 Traditional load frequency control model in two regional interconnected power grid In provincial control area A in Fig. 5, two situations (with "closed area" and without "closed area") will be set. In the previous two situations, if there is a step increment of value 1 of direct-dispatching at $20 \mathrm{~ms}$ time, ACE of provincial control area A under the two situations can be shown in Fig. 6. And some conclusions can be obtained after comparison and analysis. 


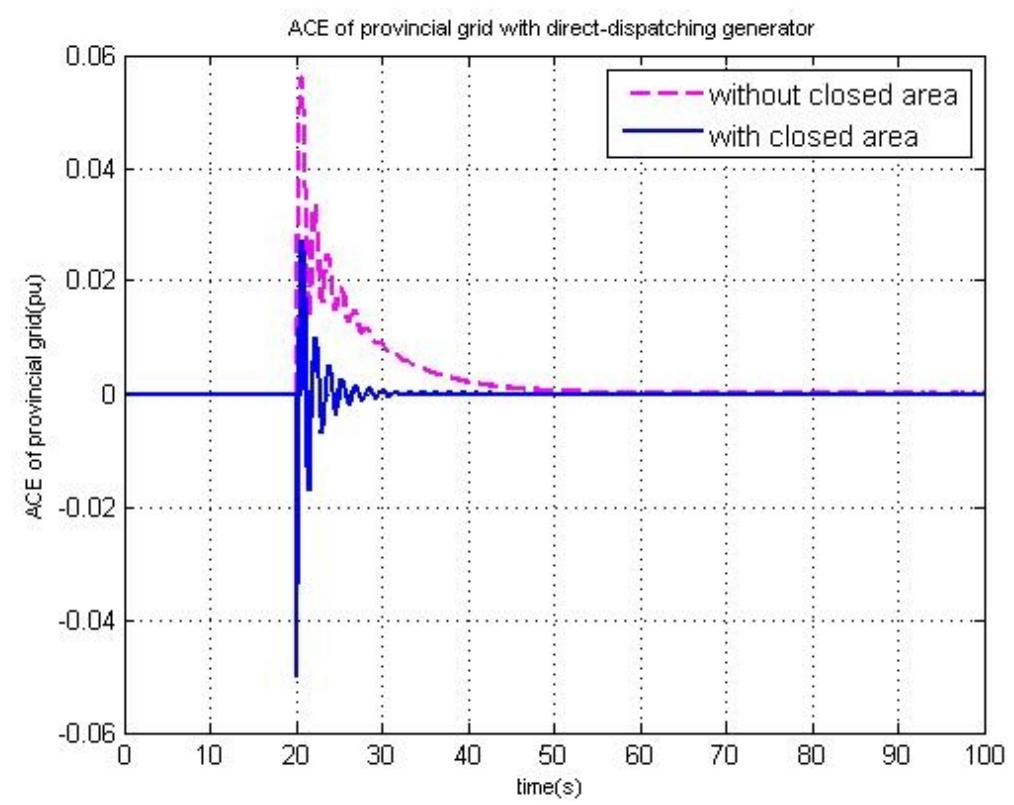

Fig. 6 ACE of province A with adequate provincial generators regulating capability

As can been seen in Fig. 6, when the output of direct-dispatching generators changes, if "closed area" method is not adopted, there will be huge fluctuation on ACE of the provincial control area in which direct-dispatching generators locate. However as there is adequate provincial generators regulating capability, ACE of province A can be still regulated to zero. If "closed area" method is adopted, there will be a small range of oscillation of ACE of province A and that is the result of some delay links in the actual power grids. And the oscillation will decrease to zero soon.

The regulating curve of the provincial generators can be shown in Fig. 7.

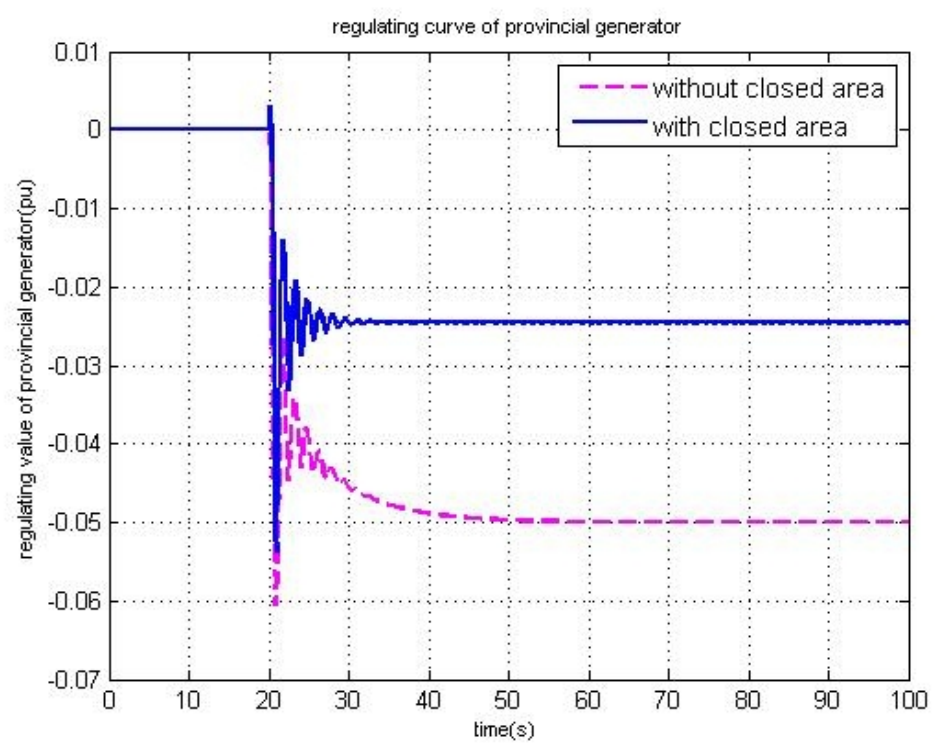

Fig. 7 regulating curve of the provincial generators with adequate provincial generators regulating capability

As can been seen in Fig. 7, when the output of direct-dispatching generators changes, if "closed area" method is not adopted, provincial generators need do many regulating actions to maintain active power balance of its own operating area. If "closed area" method is adopted, the regulating resources of provincial generators can be saved reasonably.

However, in the actual power grids, there are usually limited regulating range for each provincial generator. If the regulating range of each provincial generator is set $-0.04(\mathrm{pu})-+0.04(\mathrm{pu})$, and the same 
operating mode is set, then ACE curve of province A with inadequate provincial generators regulating capability can be gotten in Fig. 8 .

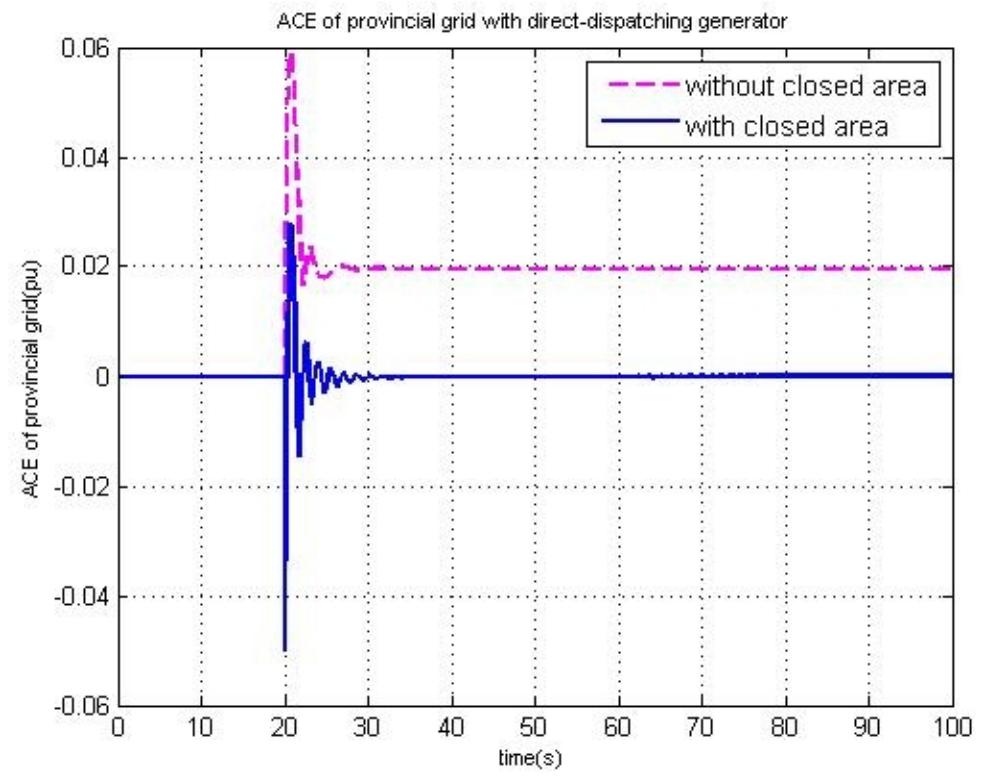

Fig. 8 ACE of province A with inadequate provincial generators regulating capability

As can been seen in Fig. 8, when the output of direct-dispatching generators changes, if "closed area" method is not adopted, ACE of provincial control area cannot be regulated to zero by provincial generators. However, the use of "closed area" method can make ACE of provincial control area be regulated to zero soon after a small range of oscillation.

The regulating curve of the provincial generators can be shown in Fig. 8.

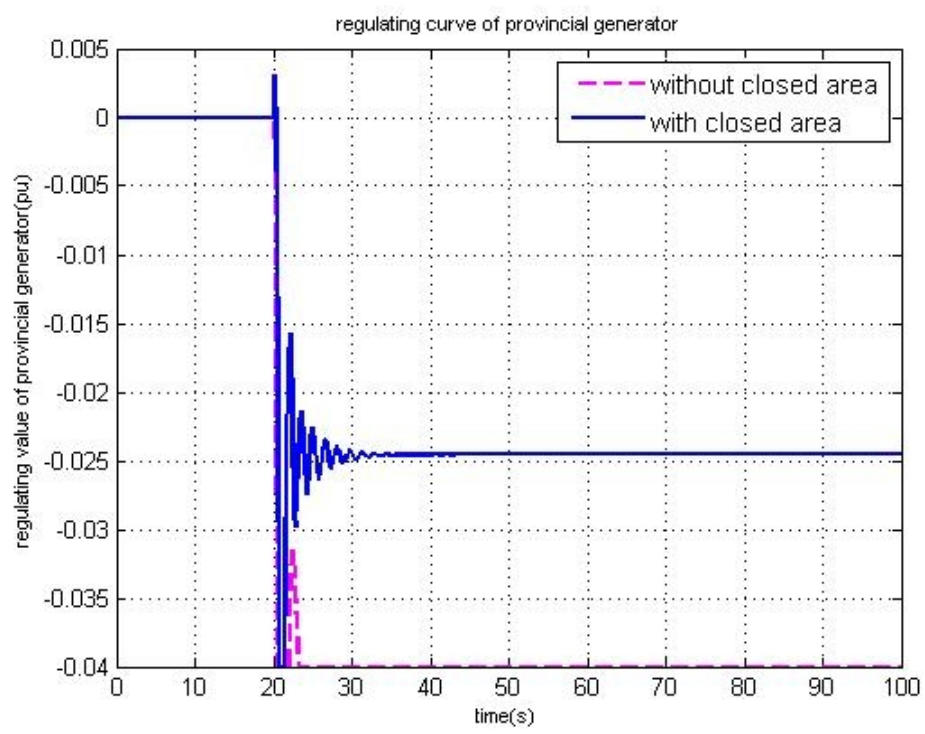

Fig. 9 regulating curve of the provincial generators with inadequate provincial generators regulating capability

As can been seen in Fig. 9, as there is regulating limitation of provincial generators, if "closed area" method is not adopted, regulating of provincial generators will come to the maximum and minimum values of their regulating easily. However, the use of "closed area" method can make provincial control area resume balance with minor regulating cost.

Above all, now that there are many delay links in actual power grid, the use of "closed area" method cannot eliminate impacts on ACE of provincial control area from direct-dispatching generators completely like the above theoretical deduction. However, "closed area" method reduces 
the impacts greatly in fact and saves the regulating cost, which is of great significance to the active balance of the area containing direct-dispatching generators.

\section{Conclusions}

In this paper, in order to solve the problem that change of output of direct-dispatching generators may have impacts on ACE of the provincial control area, "closed area" method is discussed. Detailed statement on necessity and effectiveness of "closed area" method is presented and some conclusions can be found as follows:

If "closed area" method is not adopted, the change of power output of direct-dispatching generators will influence the calculation of ACE of provincial control area in which direct-dispatching generators locate. The variable quantity of active power of direct-dispatching generators is added to ACE of provincial control area. Provincial generators need to be responsible for the change of direct-dispatching generators. When there is adequate provincial generators regulating capability, the impacts result from direct-dispatching generators will be eliminated by provincial generators. However, it takes extra provincial generators regulating resource. When provincial generators regulating capability is inadequate, ACE of provincial control area cannot be regulated to zero even. Obviously, that would do harmful to the active balance of provincial control area.

If "closed area" method is adopted, in theory, direct-dispatching would have no influence on ACE of provincial control area any more. However, in actual power grids, there are always some delay links between output links of provincial generators and calculating links of ACE of provincial control area, ACE of provincial control area will be regulated to zero soon after a small range of oscillation. Overall, "closed area" method is quite beneficial when solving the impacts on provincial control area from direct-dispatching generators and saving provincial generators regulating cost.

\section{Acknowledgements}

This work was financially supported by the National Natural Science Foundation of China (No. 51577031) and State Grid Corporation of China(Research on operation control and protection technology of large scale new energy sources connected to DC power supply system with weak synchronous support, No.NYN17201600301).

\section{References}

[1] Yan Xu, Cuilan Zhu, Weimin Zeng. Study on hierarchical AGC mode in central China power grid[J]. Automation of Electric Power Systems, 2000, 24(22): 45-47. "In Chinese".

[2] Mu Jiang, Wenchuan Wu, Boming Zhang, et al. Simulation of an AGC Coordinated Control Strategy for Ultra-high Voltage Interconnected Power System[J]. Automation of Electric Power Systems, 2010, 34(14): 75. "In Chinese".

[3] Jaleelin, Van Slyck L S, Ewart D N, et al. Understanding automatic generation control[J]. IEEE Trans on Power Systems, 1992, 7(3): 1106-1122.

[4] Green R K. Transformed automatic generation control[J]. IEEE Trans on Power Systems, 1996, 11(4): 1799-1804.

[5] Ping Wang, Qi Zhang. The Research Means and Actuality of Tie Lines Control outside and in Nation[J]. Electric Power, 2004, 19(4): 283-286. "In Chinese".

[6] N. Jaleelit, Louis Van Slyckt. NERC's new control performance standard[J]. IEEE Trans on Power Systems, 1999, 14(3): 1092-1099. 
[7] Maojun Yao, Raymond R. Shoults, Randy Kelm. AGC Logic Based on NERC's New Control Performance Standard and Disturbance Control Standard[J]. IEEE Trans on Power Systems, 2000, 14(2): 201.

[8] S Tetsuo, Dynamic K E. Analysis of Generation Control Performance Standards[J]. IEEE Trans on Power Systems, 2002, 17(3): 806-811.

[9] Zonghe Gao, Xianliang Teng. Automatic generation control strategy under control performance standard for interconnected power grids[J]. Automation of Electric Power Systems, 2005, 29(19): 40-44. "In Chinese".

[10] Zonghe Gao, Gang Chen, Junfeng Yang, et al. Active Power Control for Tie-lines in UHV Interconnected Power Grid Part One AGC Control Strategies[J]. Automation of Electric Power Systems, 2009, 33(15): 51-55. "In Chinese".

[11] Yue Hao. Study on Automatic Generation Control Mode and Performance Assessment Standard in UHV Interconnected Power Grid[D], 2014. "In Chinese".

[12] Changyi Liu, Fang Han, Jilai Yu. Study on Peak Load Frequency and Tie-line Power Flow Regulation of Interconnected Power System[J]. Power System Technology, 2003, 27(4): 36-38.

[13] Danling Wei. Research for Tie-line Power Flow Control and Adjustment of Interconnected Power System[J]. Equipment Manufactring Technology, 2003, 27(4): 36-38.

[14] Chongxin Huang. Study on several fundamental problems about area control of power systems[D], 2013. "In Chinese". 